\title{
Postglucose growth hormone nadir and insulin-like growth factor-1 in naïve-active acromegalic patients: do these parameters always correlate?
}

\author{
Nadir do hormônio de crescimento após glicose e fator \\ de crescimento insulina-símile do tipo 1 em pacientes \\ acromegálicos ativos virgens de tratamento: são \\ estes parâmetros sempre correlacionáveis?
}

${ }^{1}$ Federal University of Minas Gerais, Belo Horizonte, MG, Brazil

${ }^{2}$ University of Michigan, Department of Medicine, Division of MEND ${ }^{3}$ University of Michigan, Department of Medicine Neurosurgery, Ann Arbor, MI, USA

Correspondence to:

Antônio Ribeiro-Oliveira Jr Rua São Romão, 343/701

30330-120 - Belo Horizonte, MG, Brasil

brolivei@uol.com.br

antonioroj@@gmail.com

Received on May/18/2011 Accepted on Aug/23/2011

Antônio Ribeiro-Oliveira Jr. ' , Alex Faje², Ariel Barkan ${ }^{2,3}$

$\mathrm{T}$ The diagnosis of acromegaly is based on clinical features and biochemical criteria. While clinical suspicion is of extreme importance, laboratory evaluation is mandatory to establish the diagnosis. Growth hormone $(\mathrm{GH})$ is secreted in a pulsatile pattern. Normal individuals have undetectable levels during most of the daytime period. In contrast, $\mathrm{GH}$ is always detectable in acromegalic patients, promoting higher levels of insulin-like growth factor-1 (IGF-1) (1). Thus, even random GH levels $<1 \mu \mathrm{g} / \mathrm{L}$ do not rule out acromegaly. The two most used tests to assess biochemical activity in acromegaly are postglucose GH nadir (GHn) and IGF-1. GHn during an oral glucose tolerance test (OGTT) has been used as the standard method for acromegaly diagnosis (2), although we have recently reported suppression in low GH naïe-active acromegalic patients below the current consensus values $(3,4)$. Furthermore, it has been reported that OGTT should ideally be evaluated in relation to age (5-8), gender $(5,7)$ and body mass index $(5,8)$. Actually, there has been several attempts to define GHn in normal patients using different assays, when cutoff values were lower than $0.3(9,10)$. One report has suggested that random basal GH levels $\geq 5 \mu$ in men, and $\geq 10 \mu \mathrm{l}$ in women may possibly obviate the need of an OGTT suppression test, when IGF-1 is elevated (11). IGF-1 levels correlate with clinical features of acromegaly and are stable during the day (12). Studies have demonstrated that GHn and IGF-1 usually correlate well (13), although their relationship has not been tested in acromegalic populations with different GH outputs, and for different GHn thresholds.

Thus, we aimed at evaluating the correlation between GHn and IGF-1 levels in two different populations of clinically and biochemically naïve-active acromegalic patients: one with clearly elevated, and the other with low mean 24-h GH concentrations. We studied thirty-eight adults with untreated acromegaly (22 males, 16 females), as defined by the presence of clinical symptoms and exam results showing elevated ageadjusted IGF-1 values. Their ages ranged from eighteen to seventy-three years old. All patients had been enrolled in other reported protocols at the University of Michigan. All patients underwent frequent blood sampling for GH followed by an OGTT, when a sample for IGF-1 was also collected. A mean $24-\mathrm{h}$ GH value of $4.3 \mu \mathrm{g} / \mathrm{L}$ was used as the threshold value to distinguish "high" and "low" GH study groups. This cutoff value was chosen because it represented the highest mean 24-h GH level in our studies of normal, healthy control adults (14). Fourteen patients were defined as "high" GH acromegalic patients ( 9 males, 5 females; mean age $40.6 \pm 3.8$ years) and twenty-four as 
"low" GH acromegalic patients ( 13 males, 11 females; mean age $46.3 \pm 2.9$ years). All patients had a MRIidentifiable pituitary adenoma. A GH-secreting pituitary adenoma was histologically and immunochemically identified in all cases $(n=38)$. None of the patients had renal or hepatic impairment, and none were treated with dopamine agonists, somatostatin analogues, $\mathrm{GH}$ receptor antagonists, estrogen or any medication that could potentially affect $\mathrm{GH}$ secretion.

Participants consumed a standard isocaloric hospital diet consisting of three meals and a bedtime snack during sample collection. Blood sampling for GH was performed every ten minutes for 24 -h in all patients. Subsequently, an oral glucose load was given, followed by $\mathrm{GH}$ and glucose measurements every $10 \mathrm{~min}$ for two hours, between 07:00 and 09:00h (13 points in time), while patients were resting in a supine position. Serum GH was measured in duplicate using a chemiluminescent assay (Nichols Institute Diagnostics, San Juan Capistrano, CA, USA). Sensitivity of the GH assay reported by the manufacturer, and confirmed by our experience, was $0.01 \mu \mathrm{g} /$ liter. Plasma IGF-1 was measured using a two-site immunoradiometric assay (Diagnostic System Laboratories, Webster, TX, USA) in all samples. Age-adjusted IGF-1 values were obtained from a previously published large multicenter study by Brabant e cols. (15), which employed the same assay used in this study. Z-score calculation required the average of age-specific standard deviation reference values, since reference data showed a slightly non-Gaussian distribution.

In order to address the relationship between GHn and IGF-1 levels, we subdivided the whole group of 38 patients according to both the group of origin ("high" or "low" GH group), and to GHn cutoff value of $1 \mu \mathrm{g} / \mathrm{L}$. The relationship between logarithm-transformed GH levels and IGF-1 z-scores were analyzed by means of correlations using Spearman $r$ in each analysis. As all patients from the "high" GH group had GHn higher than $1 \mu \mathrm{g} / \mathrm{L}$, we had thus obtained two groups and two subgroups of patients according to these criteria, respectively: "high" GH group with GHn higher than $1 \mu \mathrm{g} / \mathrm{L}(\mathrm{N}=14)$, "low" GH group with any GHn value $(\mathrm{N}=24)$, "low" GH group with $\mathrm{GHn}$ higher or equal than $1 \mu \mathrm{g} / \mathrm{L}(\mathrm{N}=11)$, and "low" GH group with GHn lower than $1 \mu \mathrm{g} / \mathrm{L}(\mathrm{N}=13)$.

The two studied groups did not differ significantly in terms of age, gender, and body mass index. The 24-h individual mean GH for the "high" and "low" GH pa- tients ranged from 4.6 to 120.8 , and 0.6 to $4.0 \mu \mathrm{g} / \mathrm{L}$, respectively $(\mathrm{P}<0.0001)$. There was a significant correlation between IGF-1 z-scores and mean 24-h GH for the entire group $(\mathrm{r}=0.73, \mathrm{P}<0.0001)$. As shown in figure 1 , significant correlations between GHn and IGF-1 $\mathrm{z}$-scores were detected for both the entire group $(\mathrm{r}=0.83, \mathrm{P}<0.0001)$ and the "low" GH group $(\mathrm{r}=$ $0.72, \mathrm{P}<0.0001)$.

A

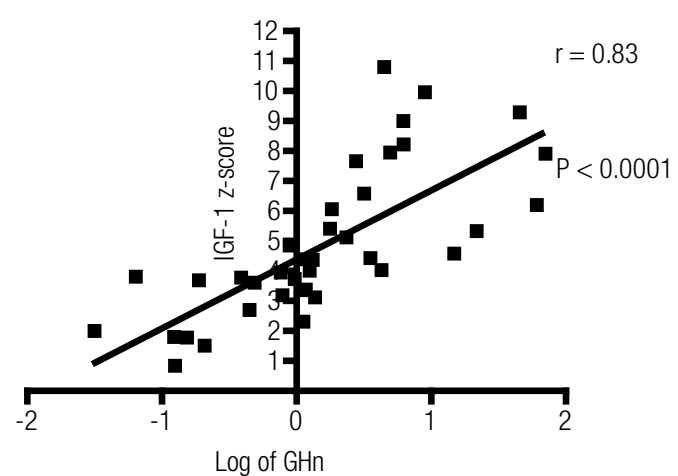

B

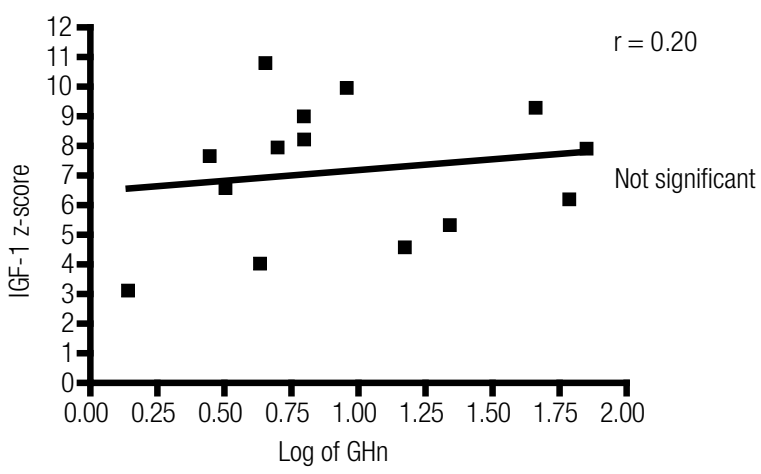

C

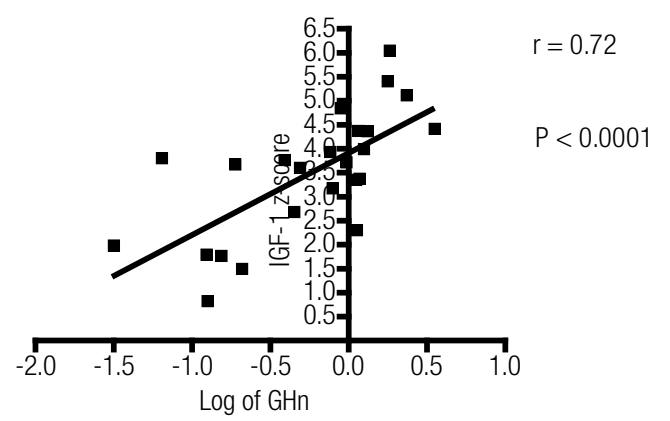

Figure 1. Correlation between the logarithm-transformed postglucose growth hormone nadir $(\mathrm{GHn})$ and insulin-like growth factor 1 (IGF-1) z-scores for the entire group $(A ; N=38)$, and both "high" $(B ; N=14)$, and "low" ( $\mathrm{C} ; \mathrm{N}=24)$ growth hormone groups.

However, GHn did not correlate with IGF-1 z-scores for the "high" GH group. As shown in figure 2, when the "low" GH group was subdivided into two 
subgroups according to the cutoff value of $l \mu \mathrm{g} / \mathrm{L}$ for GHn, those patients who showed suppression higher or equal to $\mathrm{l} \mu \mathrm{g} / \mathrm{L}$ showed significant correlation with IGF-1 $\mathrm{z}$-score $(\mathrm{r}=0.80, \mathrm{P}<0.01)$, while those who showed suppression lower than $1 \mu \mathrm{g} / \mathrm{L}$ did not show significant correlation with IGF-1 Z-score.

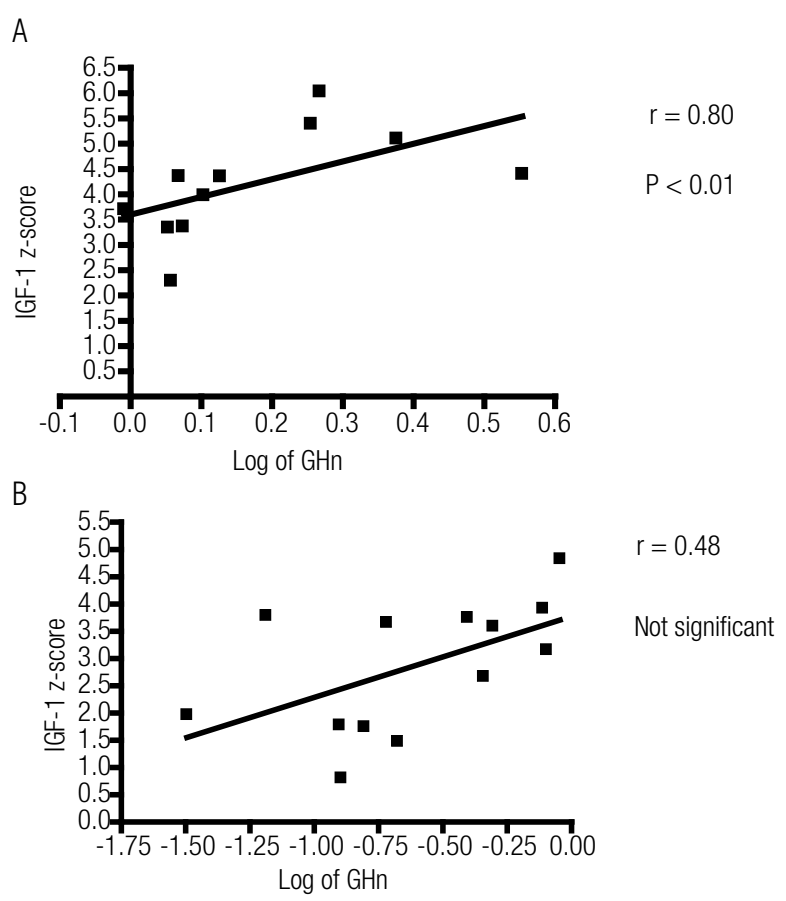

Figure 2. Correlation between the logarithm-transformed postglucose growth hormone nadir (GHn) and insulin-like growth factor 1 (IGF-1) z-scores in the "low" growth hormone group, according to the GHn cutoff value higher or equal than $1 \mu \mathrm{g} / \mathrm{L}(A ; N=11)$, or lower than $1 \mu \mathrm{g} / \mathrm{L}(B ; N=13)$.

Altogether, these data show that the correlation between GHn and IGF-1 Z-scores, although significant for the entire group, is lost in the extremes of GHn, as demonstrated for the "high" GH group, and the "low" GH group with GHn lower than $1 \mu \mathrm{g} / \mathrm{L}$. Interestingly, we have found GHn lower than $1 \mu \mathrm{g} / \mathrm{L}$ in more than $50 \%$ of our "low" GH acromegalic patients, and GHn lower than $0.4 \mu \mathrm{g} / \mathrm{L}$ in almost $30 \%$ of these patients. Moreover, we had two active female acromegalic patients, in which GHn is expected to be higher than in males, showing GHn levels as low as $0.03 \mu \mathrm{g} / \mathrm{L}$ and $0.07 \mu \mathrm{g} / \mathrm{L}$. Accordingly, a mild residual disease activity in a subgroup of treated acromegalic patients with GHn $<\mathrm{l} \mu \mathrm{g} / \mathrm{L}$ and increased IGF-1 was recently shown (16).

In conclusion, besides OGTT being superfluous in the diagnosis of acromegaly in patients with active disease and "high" GH (3), and the difficulty in interpre- ting it in relation to age, gender and body mass index (4), there is an important lack of agreement between GHn and IGF-1 when GH output is too high or too low. In the first situation, repeated baseline GH levels, instead of GHn, may be of importance in follow-up alongside with IGF-1, due to possible saturation of GH receptors (12). More importantly, in the second situation, no matter how low GHn is, it is still not enough to claim biochemical inactivity, and suppressed GHn should not, therefore, be regarded as important whenever IGF- 1 is high in acromegaly.

Disclosure: no potential conflict of interest relevant to this article was reported.

\section{REFERENCES}

1. Duncan E, Wass JA. Investigation protocol: acromegaly and its investigation. Clin Endocrinol (Oxf). 1999;50(3):285-93.

2. Giustina $A$, Chanson $P$, Bronstein MD, Klibanski $A$, Lamberts $S$, Casanueva FF, et al. A consensus on criteria for cure of acromegaly. J Clin Endocrinol Metab. 2010;95(7):3141-8.

3. Vieira Neto L, Abuchan J, Araujo LA, Boguszewski CL, Bronstein MD, Czepielewski M, et al. Recomendações do Departamento de Neuroendocrinologia da Sociedade Brasileira de Endocrinologia e Metabologia para o diagnóstico e tratamento da acromegalia no Brasil. Arq Bras Endocrinol Metab. 2011;55(2):91-105.

4. Ribeiro-Oliveira A Jr, Faje AT, Barkan AL. Limited utility of oral glucose tolerance test in biochemically active acromegaly. Eur $\mathrm{J}$ Endocrinol. 2011;164(1):17-22.

5. Arafat AM, Möhlig M, Weickert MO, Perschel FH, Purschwitz $J$, Spranger J, et al. Growth hormone response during oral glucose tolerance test: the impact of assay method on the estimation of reference values in patients with acromegaly and in healthy controls, and the role of gender, age, and body mass index. $\mathrm{J}$ Clin Endocrinol Metab. 2008;93(4):1254-62.

6. Colao A, Pivonello R, Cavallo LM, Gaccione M, Auriemma RS, Esposito F, et al. Age changes the diagnostic accuracy of mean profile and nadir growth hormone levels after oral glucose in postoperative patients with acromegaly. Clin Endocrinol (Oxf). 2006;65(2):250-6.

7. Colao A, Amato G, Pedroncelli AM, Baldelli R, Grottoli S, Gasco V, et al. Gender- and age-related differences in the endocrine parameters of acromegaly. J Endocrinol Invest. 2002;25(6):532-8.

8. Vierhapper H, Heinze G, Gessl A, Exner M, Bieglmayr C. Use of the oral glucose tolerance test to define remission in acromegaly. Metabolism. 2003;52(2):181-5.

9. Freda PU, Nuruzzaman AT, Reyes CM, Sundeen RE, Post KD. Significance of "abnormal" nadir growth hormone levels after oral glucose in postoperative patients with acromegaly in remission with normal insulin-like growth factor-l levels. J Clin Endocrinol Metab. 2004;89(2):495-500.

10. Rosário PW, Furtado MS. Growth hormone after oral glucose overload: revision of reference values in normal subjects. Arq Bras Endocrinol Metabol. 2008;52(7):1139-44.

11. Rosario PW. Measurement of basal GH in the diagnosis of acromegaly. Arq Bras Endocrinol Metabol. 2010;54(7):668-9.

12. Barkan AL, Beitins IZ, Kelch RP. Plasma insulin-like growth factor-I/somatomedin-C in acromegaly: correlation with the de- 
gree of growth hormone hypersecretion. J Clin Endocrinol Metab. 1988;67(1):69-73.

13. Dobrashian RD, O'Halloran DJ, Hunt A, Beardwell CG, Shalet SM. Relationships between insulin-like growth factor-1 levels and growth hormone concentrations during diurnal profiles and following oral glucose in acromegaly. Clin Endocrinol (Oxf). 1993;38(6):589-93.

14. Dimaraki EV, Jaffe CA, DeMott-Friberg R, Chandler WF, Barkan AL. Acromegaly with apparently normal GH secretion: impli- cations for diagnosis and follow-up. J Clin Endocrinol Metab. 2002;87(8):3537-42.

15. Brabant G, Von Zur Muhlen A, Wuster C, Ranke MB, Kratzsch J, Kiess W, et al. Serum insulin-like growth factor I reference values for an automated chemiluminescence immunoassay system: results from a multicenter study. Horm Res. 2003;60(2):53-60.

16. Elias PC, Lugao HB, Pereira MC, Machado HR, Castro M, Moreira AC. Discordant nadir GH after oral glucose and IGF-I levels on treated acromegaly: refining the biochemical markers of mild disease activity. Horm Metab Res. 2010;42(1):50-5. 